\title{
PROFESSOR BACHAREL NA EDUCAÇÃO PROFISSIONAL E TECNOLÓGICA: A BUSCA POR IDENTIDADES E O TRABALHO DOCENTE
}

\author{
Jefferson Luiz da Silva CARDOSO ${ }^{1}$ \\ Universidade Estadual do Pará - UEPA \\ jerffersonluiz@ hotmail.com \\ Albêne Lis MONTEIRO² \\ Universidade Estadual do Pará - UEPA \\ albenelis@uol.com.br
}

\begin{abstract}
Resumo: O presente artigo integra nossa dissertação de mestrado, em desenvolvimento na área da educação, e sintetiza algumas ideias surgidas no decorrer da pesquisa. Investigamos a prática pedagógica dos professores bacharéis da Educação Profissional e Tecnológica, mais precisamente os saberes pedagógicos. Partimos de uma pesquisa bibliográfica e identificamos como referências Ribas (2011), Imbernón (2011), Pimenta (2012), Bastos (2003), Freire e Carneiro (2012), Garcia (2010), Gama; Terrazzan (2012), Fagundes (2005), Furlanetto (2012), Penitente (2012), dentre outros. A formação de professores se constitui como elementar neste trabalho. Na pré-análise, observamos que a identidade é um processo de construção e reconstrução, assim como o trabalho docente deve ser observado a partir da prática pedagógica nos ambientes educacionais. Os debates no meio educacional fortalecem as reflexões acerca da prática dos professores no cotidiano da sala de aula, principalmente no enfrentamento dos desafios pedagógicos do ambiente escolar.
\end{abstract}

Palavras-chave: Professor bacharel. Educação Profissional e Tecnológica. Trabalho e identidade docente.

\begin{abstract}
This article is part of our master's dissertation, in development. We researched the pedagogical practice of teachers with bachelor's degree in Professional and Technological Education, more precisely the pedagogical knowledge. We started from a bibliographic research, identifying as references Ribas (2011), Imbernón (2011), Pimenta (2012), Bastos (2003), Freire; Carneiro (2012), Garcia (2010), Gama; Terrazzan (2012), Fagundes (2005) Furlanetto (2012), Penitente (2012), among others. The training of teachers is an elementary constituent of this work, due to the debates in the educational environment, fortifies the thoughts on the practice of teachers in the classroom routine, especially concerning the confrontation of educational challenges in the school environment. We observed that the identity is a construction and reconstruction process as well as the teaching work must be observed from the pedagogical practice in the educational environments.
\end{abstract}

Keywords: Bachelor teacher. Professional and Technological Education. Work and teaching identity.

\footnotetext{
${ }^{1}$ Mestre em Educação (UEPA), com formação inicial em Pedagogia (UFPA), Gestor de Empresas (UNAMA), Esp. em Ed. Superior (FACINTER) atualmente sou professor da SEMEC-Belém e da SEDUC/PA.

2 Possui graduação em Licenciatura Plena Em Pedagogia na Habilitação Administração Escolar (1973) e Supervisão Escolar (1975) pela Universidade Federal do Pará, mestrado em Educação, Supervisão e Currículo pela Pontifícia Universidade Católica de São Paulo (1997) e doutorado em Educação (Currículo) pela Pontifícia Universidade Católica de São Paulo (2002). Atualmente é membro da Associação Nacional de Pós-Graduação e Pesquisa em Educação e professora titular da Universidade do Estado do Pará.
} 


\section{Introdução}

A Educação Profissional e Tecnológica (EPT) tem papel fundamental para o desenvolvimento nacional, quando realizada com qualidade e teor humanizado. Observado seu caráter de formação rápida e diversificada, tem levado milhões de brasileiros para as salas de aula na promessa da empregabilidade e ascensão social. Nesse panorama, destaco a presença dos professores bacharéis como grandes responsáveis pela formação dos que procuram, nessa modalidade de ensino, a qualificação profissional que lhes possibilitará enfrentar o desafio do mundo do trabalho. Assim, é necessário que os professores bacharéis consigam compreender seu papel na sala de aula dessa modalidade de instrução. O processo de construção de sua identidade como docente tem reflexos significativos na sua prática pedagógica em sala de aula. Nessa direção, este texto tem como objetivo refletir sobre o processo de construção da identidade docente da EPT, bem como, do trabalho docente na sala de aula.

A pesquisa em andamento ${ }^{3}$ está inserida na linha de formação de professores e tem como procedimento metodológico a pesquisa bibliográfica sobre identidade e trabalho docente, com base nas obras de Ribas (2011), Imbernón (2011), entre outros. A "Revista Brasileira de Pesquisa Sobre Formação de Professores" (período 2010-2012) é outra fonte de nossa pesquisa, em que encontramos teóricos como: Bastos (2003), Freire e Carneiro (2012), Garcia (2010), Gama e Terrazzan (2012), Fagundes (2005), Furlanetto (2012), Penitente (2012), que discutem sobre identidade e trabalho docente. O estudo desses autores, entrelaçados com nossas préanálises, já nos permite chegar a algumas considerações acerca da identidade e do trabalho docente, tais como: a identidade é um processo de construção e reconstrução constante atrelado a concepções ético-político-profissionais, e que o trabalho docente deve ser demarcado principalmente pela prática pedagógica e suas nuances, como a busca pela melhor didática no ensino dos conteúdos e até mesmo de adequação do professor no ambiente escolar, situações essas imbricadas e que permeiam os debates sobre formação de professores.

\section{Identidade e trabalho docente}

O processo de formação de professores é repleto de ações e significados que possibilitam ao educador a formação de uma identidade profissional no desenvolvimento pleno

\footnotetext{
${ }^{3}$ A pesquisa em andamento tem como título "Professor Bacharel e a Didática: um desafio para a construção da identidade profissional e da formação pedagógica de docentes da escola profissional e tecnológica". Possui como objetivo geral Analisar a formação de professores bacharéis com relação aos saberes pedagógicos e o desafio da prática docente na sala de aula da educação profissional e tecnológica.
} 
da docência, sendo esse professor parte do processo de desenvolvimento das pessoas e da sociedade (RIBAS, 2005). O universo da educação tão grandioso e repleto de experiências traz consigo grandes questões a serem investigadas, como é o caso deste trabalho, na tentativa de compreender como se dá a ação do docente bacharel na EPT, que passa pela superação de sua formação inicial.

Refletir sobre o processo de formação profissional também requer, de certo modo, perceber, ao longo da história docente, como se deu a constituição do ser professor, no desenvolvimento de sua prática educativa. Nessa direção, algumas perguntas são importantes para compreender os avanços e retrocessos na formação de professores, tais como: "o que fazia e como fazia; o que pensava e como pensava; como esse processo ocorria. Em outras palavras, qual a realidade social a qual todos estávamos/estamos envolvidos.” (BASTOS, 2003, p.170), no sentido amplo de reviver, em um movimento dialético, o cotidiano escolar como o terreno das atividades docentes.

Pensar na formação de professores para a EPT tem remetido a determinadas preocupações: como esses professores organizam seus trabalhos pedagógicos, como eles articulam seus conhecimentos e modos de aprendizagem no contexto atual, diverso e complexo (OLIVEIRA e SILVA, 2012). Ainda se agrava a situação por conta de a LDB 9394/96 não abordar a temática de forma específica (MACHADO, 2008), o que torna a situação um verdadeiro desafio para a atuação do bacharel como docente na EPT. Diante disso, muitas vezes, "o professor sente-se perdido, não sabe o que fazer, mas é obrigado a agir por ensaio e erro e encontrar saídas que, embora lhe pareçam melhores, nem sempre dão bons resultados." (RIBAS, 2005, p.15). De igual forma, Tardif (2014) evidencia que, nos dias de hoje, ainda há professores que aprendem por tentativa e erro, o que acentua a necessidade da superação da formação inicial dos professores bacharéis, haja vista o não contato com a questão pedagógica que lhe possibilitaria melhor condução da ação docente.

Da mesma maneira, pouco se vê um debate mais acentuado por parte das instituições de nível superior sobre a docência do professor bacharel (FREIRE e CARNEIRO, 2012) foca-se tão somente em uma formação voltada para pesquisa, abandona-se a oportunidade da sala de aula como desenvolvimento de carreira. Na ótica de Duran (2010), o que se percebe no Brasil é um processo de formação aligeirada tanto de formação inicial quanto de formação continuada de professores.

No caso dos profissionais bacharéis atuantes na EPT, é importante a compreensão de que esses profissionais optaram por estar nas salas de aulas em virtude da possibilidade de 
trabalho, e que, de forma automática, utilizam-se dos saberes da experiência na condução das aulas (TARDIF, 2014; PIMENTA, 2012), mas que sofrem o impacto do cotidiano escolar ainda mais asseverado que os professores oriundos das licenciaturas, cursos com essência na formação inicial de professores. Sobre esse impacto do trabalho docente, cabe saber que "os primeiros anos de profissão são decisivos na estruturação da prática profissional e podem ocasionar o estabelecimento de rotinas e certezas cristalizadas sobre a atividade de ensino que acompanharão o professor ao longo de sua carreira." (NONO, 2011, p.19). De igual forma, argumenta Zanchet (2012) quando enfatiza que os anos iniciais são os que têm maior choque na vida profissional do professor, o que exige desses profissionais muito empenho para que aconteça de forma verdadeira a práxis educativa.

A partir do momento inicial, o profissional bacharel que atua como docente na EPT começa a internalizar a questão da identidade docente, que, na perspectiva de Garcia (2010), forma-se paulatinamente pela aprendizagem informal, resultado de sua vida como acadêmico e das situações ocorridas na graduação. Nesse momento, o bacharel ao reviver as situações da universidade refaz, repensa e reconstrói ideias e experiências vivenciadas no passado (BASTOS, 2003). Experiências que hoje se tornam presentes em sua atuação como docente diante da educação formal, que envolve o ensino, a instrução e conhecimentos mais elaborados (RIBAS, 2005).

No entanto, ser docente envolve uma gama de conhecimentos além da formação inicial, que, em verdade, prepara-nos para as situações mais conhecidas: realizar uma aula, elaborar uma prova e passar trabalhos. Ser docente é percorrer caminhos dificultosos na direção de um saber adquirido ao longo de uma carreira que nem sempre é fácil. Pois, segundo Castro (1995) apud Nono (2011, p.28), o desafio inicial da formação docente vai além, visto ser

[...] marcado pelas dificuldades de adaptação pessoal e profissional, pela insegurança e despreparo, por certas dificuldades em lidar com situações específicas da prática, pelo isolamento, pela ausência de comunicação entre os próprios colegas de profissão e de apoio em busca de solução para os problemas e imprevistos da rotina escolar.

No contexto da EPT, é comum o cenário acima descrito, principalmente pela não vivência dos professores bacharéis com o cotidiano escolar na graduação, como é o caso dos licenciados, que têm o estágio supervisionado como forma de integração teoria-prática. No entanto, é necessário que a formação do profissional bacharel seja construída nas bases sólidas da formação de professores, que, por certo, não pode ser vista como mera acumulação de 
experiências, mas sim por um processo crítico-reflexivo de constituição permanente de uma identidade pessoal Bastos (2003), presente nos cursos de formação de professores.

Dentre muitos motivos, a EPT tem um caráter diferenciado na sociedade brasileira, haja vista seu fundamento estar atrelado aos movimentos político, econômico e social de cada tempo histórico, e por formar rapidamente mão-de-obra. Não seria diferente com a formação de professores dessa modalidade. Não obstante, Ribas (2005) evidencia a necessidade de mudanças nos cursos de formação inicial e continuada de professores, já que, por vezes, se idealiza uma realidade que nunca se materializa. Em termos da EPT, isso se agrava com o constante avanço tecnológico, que tira o ensino da mera transmissão de conhecimento e evidencia novas habilidades, principalmente com relação à transposição didática dos conteúdos que se esperam do professor.

A escola, como fonte de aprendizagens, tem importante papel na formação do professor, mesmo porque ela agrega um mundo de saberes que são fundamentais ao fazer docente. A criação de espaços coletivos dentro do ambiente escolar é visto como uma possibilidade grandiosa de trocas de experiências e conhecimentos acerca do trabalho docente. De acordo com Nono (2011, p. 37), esses ambientes representariam

[...] mais que a criação de um espaço de colaboração entre professores, a possibilidade de reconhecimento público dos conhecimentos profissionais docentes, inclusive daqueles pertencentes aos principiantes.

No que se refere à perspectiva do espaço escolar, Gama e Terrazzan (2012) avaliam que esse ambiente não está exclusivamente fechado aos muros da escola, mas deve ser pautado em ações ancoradas na unidade escolar, baseado em um plano de ação que contenha direcionamentos para mudar as práticas individuais e coletivas no cotidiano escolar. Lançamos mão dessa ideia à prática docente, que, diante de todo um contexto, pode ser modificada na intenção de atender à demanda institucional, como forma de compreensão da realidade e de possibilidade de intervenção, mesmo porque "o mundo do trabalho demanda por indivíduos que possam atuar em um ambiente de produção de conhecimento e, também, de transferência a outros contextos em constante transformação.” (MOURA, 2014, pp.77-78).

Dado o exposto, Ribas (2005) analisa que há necessidade da implantação de políticas públicas de formação de professores que propiciem melhores condições de trabalho, desenvolvimento pessoal e profissional. É nessa direção que a formação de professores para a EPT precisa agir: olhar o docente bacharel como um mediador do conhecimento que carece 
estar atento às mudanças ocasionadas principalmente pelo avanço da globalização, que interfere de forma direta nas relações sociais e, exclusivamente, na formação profissional dos egressos da modalidade de ensino em questão. Todas essas situações confluem para uma atuação docente pautada em uma postura crítico-reflexiva da prática educativa.

Entendemos que, na EPT, a exigência sobre os professores bacharéis acontece com mais ênfase. Isto porque a formação desses profissionais está voltada ao desempenho de atividades para o mundo do trabalho, como já foi aludido no decorrer deste estudo, já que, com a globalização, o uso das tecnologias da informação e comunicação exige dos professores da EPT solidez em sua formação (URBANETZ, 2011), o que deveria acontecer na sua constituição inicial. No entanto, por se tratar de bacharéis, a questão pedagógica tem suscitado grandes discussões e gerado uma fonte rica na superação desse quadro.

No interior da EPT, o conhecimento específico necessário para a conclusão dos cursos técnicos faz parte do desenho curricular de formação dos professores bacharéis nas diferentes áreas de conhecimento. Porém, "para ensinar bem sabemos que o conhecimento da matéria não é um indicador suficiente da qualidade do ensino." (GARCIA, 2010, p.13), sendo imperioso que as formas de como fazer o educando apreender esse conhecimento deve nortear a profissão docente em exercício que, segundo Pimenta (2012) e Tardif (2014), é adquirido por meio dos saberes pedagógicos, essência da atividade docente. Ao analisar a formação inicial do professor bacharel, percebemos de maneira clara que os saberes específicos das diversas áreas do conhecimento são enfatizados, no entanto, cabe a observação de que lhe falta a formação pedagógica (MOURA, 2014) como prática no desenvolvimento da carreira docente. Nesse caminho,

Se revisarmos as redes curriculares dos programas de formação docente, encontraremos uma clara fragmentação e descoordenação entre os diferentes tipos de conhecimento aos quais nos referimos. Os conteúdos disciplinares e os conteúdos "pedagógicos" se apresentam, de modo geral, de maneira isolada e desconexa. (GARCIA, 2010, p.14).

Na leitura do excerto acima, entendemos que até na formação de professores ocorre a separação do conhecimento necessário ao fazer docente na sala de aula, o que é muito preocupante. Pois é desejável que os professores saiam das universidades com a habilitação completa, de maneira que ele possa ser encaminhado às salas de aula sem dúvidas quanto aos conhecimentos tácitos do ofício de professor. Nesse sentido, é importante que os professores tomem posição e construam sua profissão de forma assertiva, principalmente no 
estabelecimento de valores e normas que estejam de acordo com a demanda atual que exige a profissão, como pontua Ribas (2005), e, assim, fortalecer uma participação verdadeira e coletiva desta atividade profissional (IMBERNÓN, 2011).

Em consequência, observamos que a profissão de professor tem tomado um caráter dinâmico e crítico diante das novas demandas sociais, o que tem permitido aos professores, de forma individual e coletiva, compreender sua profissão como prática social, construir e reconstruir seus saberes/fazeres, na constituição de sua identidade profissional (FAGUNDES, 2005). Em contraponto, a mera transmissão de conhecimentos, baseada em uma perspectiva técnico-conteudista, "a isto se acrescenta uma concepção técnico-instrumental da docência, além de que não revelam compreensão do que seja o currículo por competência proposto pelas diretrizes nacionais de formação." (FREIRE e CARNEIRO, 2012, p.3) e acaba por perceber o professor como mero detentor do conhecimento a ser repassado.

Vale relembrar que a educação geral voltada para a construção da cidadania está além do mero acúmulo de conhecimentos, e, em tempos de inovações tecnológicas, o professor da atualidade necessita compreender que

Educação geral, que permite tanto buscar e criar informações como usá-las para solucionar problemas concretos, é preparação para o trabalho e para o exercício da cidadania. Na verdade, qualquer competência requerida no exercício profissional, seja ela psicomotora, socioafetiva ou cognitiva é um refinamento das competências básicas. Essa educação geral permite a construção de competências que se traduzem em habilidades básicas, técnicas ou de gestão (BERGER FILHO, 1999, p.3).

Diante desse cenário, o trabalho docente ganha ainda mais atribuições, uma vez que, pela constante exigência da sociedade no que diz respeito à qualidade dos serviços públicos, dentre eles a educação, o professor se perceba como fonte rica de saberes e experiências que lhe permita o convencimento de que não se trata de um mero transmissor de conhecimentos, mas um agente que possibilita a criação e produção de novos conhecimentos (FREIRE, 2013), e isso acontece a partir de um olhar sobre a identidade do professor, em sua atividade docente.

No caso dos professores bacharéis essa construção deve ser observada a partir de uma formação continuada, haja vista a ineficiência pedagógica de sua formação inicial. Gama e Terrazzan (2012) defendem um olhar cuidadoso sobre práticas individuais e coletivas dos professores, em que o planejamento de seu trabalho docente precisa conter suas necessidades mais específicas e que possam, dessa forma, produzir melhores resultados de seu trabalho no cotidiano escolar. Nos estudos de Machado (2008), sua argumentação gira em torno de uma 
valorização para a formação de professores da EPT que supere as ações improvisadas do passado, sugerindo que essa valorização seja realizada de acordo com as dispensadas aos professores licenciados.

Tudo isso tem contribuído para a dificuldade de reconhecer a identidade do professor bacharel. Assim, cabem as contribuições de Fagundes (2005), quando este revela não ser tão produtiva a mera atribuição da identidade profissional do professor, "mas compreendê-la como um devir, ou seja, sua condição é devir, é vir a ser, considerando que o devir é o modo de ser mesmo do ser, e é o ser professor que está sempre em construção.” (Ibidem, p.182), mesmo na superação dos desafios que o cotidiano da sala de aula traz para essa construção, pois é na superação desses conflitos e desafios que os professores exercem sua profissão, conforme aponta Furlanetto (2012), sendo, assim, providos da identidade docente.

Nessa perspectiva sobre a construção da identidade do docente bacharel que atua na EPT, concordamos com as ideias de Garcia (2010), quando o mesmo elucida acerca do assunto:

Essa identidade não surge automaticamente como resultado da titulação, ao contrário, é preciso construí-la e modelá-la. E isso requer um processo individual e coletivo de natureza complexa e dinâmica, o que conduz à configuração de representações subjetivas acerca da profissão docente (Idem, p.18).

Ao entrar nas salas de aula como docente, o profissional bacharel terá contato com um terreno fértil e rico em possibilidades de atuação, o que reverbera, como no dizer de Furlanetto (2012), na prática e nas reproduções subjetivas, sobre a profissão em que ele se encontrará docente. Nas observações de Imbernón (2011), o conceito de profissão é resultado de um produto ideológico e contextual, sendo a ideologia uma influência sobre a prática profissional, uma vez que ela é legitimada pela sociedade na sua conjuntura, mediante a função social que desempenha na coletividade. O autor vai além quando assegura que é necessário ver o docente como um profissional repleto de habilidades especializadas que determinam sua competência diante do trabalho que exerce. Dessa forma, "a identidade profissional é um empreendimento coletivo" (FAGUNDES, 2005, p.186).

Tal empreendimento, como citado, é fundamental para esses professores bacharéis, em virtude das demandas ocasionadas por sua atuação na EPT, já que esta modalidade de ensino exerce sobre esses "docentes" grande desafio, ao mesmo tempo em que seu papel na sociedade moderna, 
[...] vai além da instrumentalização para a empregabilidade. Evidentemente, não se nega a importância dos conhecimentos técnicos e tecnológicos inerentes à formação, mas não se restringe a esses. Assim, ratifica-se a importância da formação humana integral, omnilateral, na perspectiva da autonomia e da emancipação [...] (MOURA, 2014, p.56).

Por essa forte influência que a EPT exerce sobre seus docentes, é necessário repensar o modo como essa identidade profissional vem sendo construída ou pelo menos alinhavada, já que grande parte dos profissionais bacharéis não se veem professores, mas sim que ocupam determinado posto em um ramo da educação. Nessa direção, o professor reconhece que novos rumos de trabalho e aprendizagens de seu ofício são necessários, principalmente quando no exercício de sua função no interior da escola (IMBERNÓN, 2011). Como bem assinala Berger Filho (1999), na afirmação de que a parceria escola (mundo do trabalho para esse profissional) é uma necessidade para concretude da EPT, baseada principalmente em um fazer pedagógico (do professor), criador de condições adequadas de formação dos cidadãos.

De fato, o espaço escolar da EPT, com todos os seus arquétipos institucionais, direcionados à produção de mão-de-obra qualificada para o mundo do trabalho, exige uma prática docente consistente e de qualidade por parte dos bacharéis e que estes correm atrás de uma reconhecida identidade docente para que possam reivindicar uma formação profissional mais justa com base na realidade da classe. Assim, como afirma Furlanetto (2012, p.120), “o que se busca é a unidade do Eu com base em uma capacidade discursiva capaz de construir uma identidade unificada e reivindicada.", como é o caso da classe docente da EPT.

$\mathrm{Na}$ concretude de uma identidade ainda indefinida, muitas vezes pela formação inicial dos professores bacharéis, existem direcionamentos, como os apontados por Freire e Carneiro (2012, p.12), ao exporem que o saber ensinar "requer a formação de um docente cuja identidade revela um sujeito epistêmico e hermenêutico, produtor de saberes e de sentidos.”, atributos que fazem parte sim do cotidiano dos docentes da EPT. No entanto, por ineficiências de políticas (MACHADO, 2008) mais refinadas na direção da formação de professores para essa modalidade, eles ainda caminham de forma quase empírica e pelo estímulo das vivências em sala de aula.

Sobre a formação da identidade do professor, Fagundes (2005, p. 188) conclui,

[...] a identidade não é um dom, nem um dado imutável, nem se transmite; não é uma coisa, porém é constituída pelas relações que o professor, enquanto sujeito histórico estabelece com os outros sujeitos dentro do processo de construção, apropriação e transmissão do conhecimento. 
Tal afirmação concentra grandes questões apresentadas ao longo dessa discussão, focadas, por exemplo, na relação teórico-prática, na postura crítico-reflexiva, na construção histórico-social da figura do professor e na manifestação dos saberes docentes como forma de efetivação da práxis educativa. Isso porque "produzir a vida do professor implica valorizar, como conteúdos de sua formação, seu trabalho crítico-reflexivo sobre as práticas que realiza e sobre suas experiências compartilhadas." (PIMENTA, 2012, p.33). Acredita-se, que a falta de uma identidade estabelecida esteja vinculada também ao fato de que uma parcela muito pequena de pessoas conhece, tem acesso a informações sobre a EPT, e menos ainda sobre a docência nessa modalidade de ensino. Ademais, a construção de um Programa Nacional de Formação Docente da Educação Básica e da Educação Profissional ${ }^{4}$ é urgente, como afirma Moura (2014), e deve, finalmente, reconhecer esse profissional como produtor e difusor do conhecimento no interior da EPT.

Superada inicialmente a questão da identidade do docente bacharel, passamos a discutir sua atuação a partir do trabalho docente. Far-se-á um debate teórico na tentativa de situar o professor bacharel em pleno desenvolvimento de suas funções docentes. Para começar, acreditamos na mudança da práxis educativa por meio de sua análise crítica. Assim, "do ponto de vista profissional, a melhoria do trabalho do professor deve se fazer pela reflexão de sua própria prática pedagógica.” (PENITENTE, 2012, p.31). Na tentativa sempre da superação dos desafios impostos pela própria sociedade, em que a escola formadora dos cidadãos urge por professores que dominem os processos de sua função: o trabalho docente, ação que demanda a tão discutida aplicação da teoria e da prática.

É importante, nesta análise, compreender o trabalho docente como repleto de incertezas e desafios, haja vista que grande parte de suas ações, senão todas, estarem voltadas à consecução de objetivos, nem sempre materiais, como da reprodução de determinado saber na produção de um carro, por exemplo. Trata-se, em verdade, de lidar com o ser humano, que passa a ser então objeto de seu trabalho, individual ou socializado, estabelecem suas relações e encaminham aos docentes problemas que lhes fazem mover seus saberes na tentativa de soluções dessas demandas, diversas vezes complexas e que se tornam grandes obstáculos aos professores (TARDIF, 2014). Nessas situações, o trabalho docente deve agir como fonte rica de possibilidades e reflexões acerca das ocorrências explicitadas pelos alunos.

\footnotetext{
${ }^{4} \mathrm{O}$ referido programa ainda está em fase de debate no Ministério da Educação.
} 
Outra dificuldade que os docentes da EPT enfrentam está relacionada à "precariedade das condições contratuais, institucionais, de trabalho e a inexistência de concursos públicos específicos para essa modalidade." (SHIROMA e LIMA FILHO, 2011, p.735 grifos nossos). Alerta-se que a falta de concursos seja um dos maiores desafios a ser superado na EPT, isto porque qualquer que seja o profissional concursado trabalha exultante e consegue desenvolver suas atividades com maior tranquilidade e qualidade. Não se trata, aqui, de dizer que os professores contratados não fazem um bom trabalho, a situação diz respeito à falta de uma política eficiente a uma profissão que tem a idade do Brasil.

Nesse cenário de grandes embaraços acerca do trabalho docente do profissional bacharel na EPT, Moura (2014) já aponta que uma grande discussão precisa ser travada pelos grupos de trabalho de formação de professores, presentes principalmente nas Universidades Federais, de forma que possam colocar em pauta as demandas efetivas dos professores bacharéis, dentre elas, concordamos com o autor sobre as pautas urgentes:

Organização e planejamento da prática pedagógica na educação profissional; avaliação do processo de ensino-aprendizagem na educação profissional; concepção de formação que se sustente numa base humanista; concepção de docência que impregne a prática desse profissional quando sua atuação se dá no mundo do trabalho (Ibidem, p.98)

Percebemos, de forma muita acertada nas ideias do autor, que o trabalho docente tem sido um grande gargalo a ser estudado pelas instâncias epistemologicamente responsáveis por essa questão, no caso, as Universidades Federais e seus grupos de estudo. Também é possível ver certo descaso com a causa, uma vez que a EP, como modalidade de ensino elencada em nossa lei maior da educação (a LDB) já vem de um passado distante e de sobremaneira muito afirmativa em suas contribuições para o desenvolvimento nacional.

Nas argumentações de Manfredi (2002) e Araújo (2007), a EP tem caminhado lado a lado com o desenvolvimento do país, sendo decisiva em grande parte de sua história, principalmente no Brasil Colônia e Império. Hoje, como já discorrido neste trabalho, agregou a questão tecnológica, sendo chamada EPT (MOLL, 2010). E continua não a principal modalidade de ensino, mas a que com mais rapidez responde às evoluções sociais no atendimento à profissionalização do povo.

Diante de tantos obstáculos a superar, o docente, no curso de seu trabalho, nem sempre consegue responder de imediato aos questionamentos dos alunos, apesar de que "os professores precisam tomar decisões e desenvolver estratégias de ação em plena atividade sem poderem se 
apoiar num "saber-fazer" técnico-científico que lhes permita controlar a situação com toda certeza" (TARDIF, 2014, p.137). Por isso, a visão de um profissional qualificado para a função é essencial, já afirma Pimenta (2012), e pensa-se, dessa maneira, que a qualificação promove nos trabalhadores condições reais capazes de aumentar seus saberes para, assim, intervir nos problemas com soluções mais concretas e eficazes. No caso dos professores, essa qualificação estimula os alunos nos estudos e lhes direciona na busca do conhecimento, para que sejam capazes de encontrar as soluções para os problemas teóricos e práticos do cotidiano (MOURA, 2014).

Nessa reflexão, o professor, como agente de transformação da realidade educacional e de sua própria práxis educativa, é capaz de compreender sua posição e seu trabalho, a partir de uma leitura crítica sobre sua prática docente individual, mas também de forma coletiva (AZZI, 2012), na premissa de que, com a socialização tanto do sucesso como das incertezas, possam avançar na direção da formação tão desejada pela EPT.

Na EPT, a questão da vivência no exercício da profissão docente recebe ainda mais ênfase quando observamos nos cursos técnicos profissionais a questão das aulas práticas, o que tem exigido esforço dos professores bacharéis em relação ao seu planejamento pedagógico, ingrediente fundamental do trabalho docente. Em uma análise bem esclarecida, Melo (2010) pontua com exatidão o cotidiano da EPT, com efeito:

\begin{abstract}
À própria natureza da educação técnica ou tecnológica, que compreende atividades teóricas e práticas mais contíguas, e, por conseguinte, requer espaços físicos diferenciados além de salas de aula, como laboratórios, oficinas e, muitas vezes, ambientes externos do campo profissional. Exige ainda tempos e relações distintas entre professores e alunos, sobretudo nas aulas práticas, organizadas em grupos menores de alunos; visitas técnicas a contextos reais de atuação profissional; estágios supervisionados; orientações em projetos, pesquisas aplicadas, entre outras. Essa variabilidade traz implicações para o trabalho docente, conferindo-lhe maior flexibilidade e proximidade na relação com os estudantes e com outros contextos e ambientes de trabalho (Ibidem, p.2).
\end{abstract}

A partir desse panorama, fica mais visível a questão dos meandros do trabalho docente na EPT, uma articulação contínua entre as teorias vividas nas salas de aula, que, em seguida, são colocadas em prática nas aulas técnicas, nos estágios e nos laboratórios, espaços privilegiados na formação profissional e que demandam a mobilização de uma gama de conhecimentos na condução dessas atividades. No direcionamento dessas situações, Romanowski (2007) explica que o professor, ao fazer a transposição do conhecimento teórico 
ao prático, privilegia a reflexão crítica dos alunos, bem como possibilita a avaliação constante de seu trabalho docente. Cabe ao professor bacharel compreender que, no interior da EPT, seu papel vai além da mera transmissão de conhecimento acumulado pela humanidade ao longo dos tempos, trata-se de promover uma educação baseada na constante crítica sobre as determinações sociais em que vivem: questões de ordem política, econômica e cultural, para que, a partir daí, consigam pensar na construção de novos conhecimentos que, na realidade, se voltem às necessidades sociais e coletivas da humanidade (MOURA, 2014), premissa que precisa nortear todo o trabalho docente do bacharel.

Assim, também o trabalho docente na EPT tem assumido um papel interessante no cenário educacional brasileiro. Mesmo com o baixo nível da pesquisa acadêmica sobre os professores bacharéis dessa modalidade de ensino, vê-se que "é oportuno destacar como um ganho relevante o seu reconhecimento como uma alternativa de educação de qualidade e com potencial de satisfazer as exigências de uma formação consistente.”. (MELO, 2010, p.5) referenda, dessa maneira, conhecimento sobre sua identidade e a qualidade de seu trabalho como agente formador.

\section{A guisa de conclusão}

O debate acerca do trabalho docente é permeado por inúmeras situações que se modificam a partir das realidades que se encontram. No entanto, segundo Tardif (2014), o trabalho docente evidencia que o professor não é um trabalhador que se contente com a mera aplicação de saberes. Antes de mais nada, é sujeito de seu próprio trabalho, pois é ele quem está em pleno contato com os alunos para, assim, negociar, improvisar e, por fim, adaptar-se para conseguir seu objetivo maior, que é o de fomentar uma educação de caráter emancipatório.

Concordamos com as proposições de Moura (2014), uma articulação entre as instituições formadoras e uma aproximação entre as esferas federal, estadual e municipal seria capaz de fomentar um projeto de formação que verdadeiramente trate o trabalho docente na EPT com a dignidade e qualidade que se merece, com vistas a suprir a necessidade didáticopedagógica que o trabalho docente exige, e que está ausente na formação inicial dos professores bacharéis.

Outrossim, considerar a construção da identidade docente um fator de extrema necessidade, principalmente na EPT, compreende que a questão da identidade perpassa pelo 
significado social que a função exerce é fundamental e, ainda, necessita de reflexões mais aprofundadas.

\section{Referências}

ARAÚJO, Ronaldo Marcos de Lima. A Educação Profissional no Pará. Belém, EDUFPA, 2007.

AZZI, Sandra. Trabalho docente: autonomia didática e a construção do saber pedagógico. In: PIMENTA, Selma Garrido. Saberes pedagógicos e atividade docente. 8 ed. São Paulo: Cortez, 2012.

BASTOS, Maria Helena Camara. Memoriais de professoras: reflexões sobre uma proposta. In: MIGNOT, Ana Chrystina Venancio; CUNHA, Maria Teresa Santo. Práticas de memória docente. São Paulo: Cortez, 2003.

BERGER FILHO, Ruy Leite. Educação profissional no Brasil: novos rumos. OEI Ediciones Revista Iberoamericana de Educación Número 20. Mayo - Agosto, 1999. Disponível em: http://www.oei.es/, acessado em: 20 jul 2015.

DURAN, Marília Claret Geraes. Profissão docente: desafios de uma identidade em crise. Revista Brasileira de Pesquisa sobre Formação Docente. Vol. 2, nº2, Jan-Jul: 2010. Disponível em: http://formacaodocente.autenticaeditora.com.br/, acessado em: 30 jun 2015.

FAGUNDES, José. Et al. O professor em busca de sua identidade. In: RIBAS, Mariná Holzmann; Et al. Formação de Professores: escolas, práticas e saberes. Ponta Grossa: Ed. UFPG, 2005.

FREIRE, Ludmila de Almeida; CARNEIRO, Isabel Magda Said Pierre. Reflexões sobre o trabalho docente do professor bacharel: perspectivas para a formação continuada. XVI ENDIPE - Encontro Nacional de Didática e Práticas de Ensino - UNICAMP - Campinas - 2012. Disponível em: www.infoteca.inf.br/endipe/smarty/templates/arquivos.../2707d.pdf, acesso em: 10 jan 2015.

FREIRE, Paulo. Pedagogia da autonomia: saberes necessários a prática docente. $46^{\mathrm{a}}$ ed. Rio de Janeiro: Paz e terra, 2013.

FURLANETTO, Ecleide Cunico. Os processos de construção identitária docente: a dimensão criativa e formadora das crises. Revista Brasileira de Pesquisa sobre Formação Docente. Vol. 4, nº, Jan-Jul: 2012. Disponível em: http://formacaodocente.autenticaeditora.com.br/, acessado em: 30 jun 2015.

GARCIA, Carlos Marcelo. O professor iniciante, a prática pedagógica e o sentido da experiência. Revista Brasileira de Pesquisa sobre Formação Docente. Vol. 2, nº3, Ago-Dez: 2010. Disponível em: http://formacaodocente.autenticaeditora.com.br/, acessado em: 30 jun 2015. 
MACHADO, Lucília Regina de Souza. Diferenciais inovadores na formação de professores para a educação profissional. Revista Brasileira da Educação Profissional e Tecnológica, v. 1 , p. 8-22, 2008.

MANFREDI, Silvia Maria. Educação Profissional no Brasil. São Paulo: Cortez, 2002.

MELO, Savana Diniz Gomes. Trabalho docente na educação profissional. In: OLIVEIRA, D.A.; DUARTE, A.M.C.; VIEIRA, L.M.F. DICIONÁRIO: trabalho, profissão e condição docente. Belo Horizonte: UFMG/Faculdade de Educação, 2010. CDROM. Disponível em: http://www.gestrado.org/pdf/428.pdf, acessado em 30 jul 2015.

MOLL, Jaqueline; Et al. Educação Profissional e Tecnológica no Brasil contemporâneo. Porto Alegre: Artemed, 2010.

MOURA, Dante Henrique. Trabalho e formação docente na educação profissional. Curitiba: Instituto Federal do Paraná, 2014.

NONO, Maévi Anabel. Professores iniciantes: o papel da escola em sua formação. Porto Alegre: Mediação, 2011.

OLIVEIRA, Viviane Souza de; SILVA, Rosália de Fátima e. Ser bacharel e professor: dilemas na formação de docentes para a educação profissional e ensino superior. Disponível em: http://www2.ifrn.edu.br/ojs/index.php/HOLOS/article/view/ 913, acessado em: 20 jul 2015 .

PENITENTE, Luciana Aparecida de Araujo. Professores e pesquisa: da formação ao trabalho docente, uma tessitura possível. Revista Brasileira de Pesquisa sobre Formação Docente. Vol. 4, no7, Jul-Dez: 2012. Disponível em: http://formacaodocente.autentica editora.com.br/, acessado em: 30 jun 2015.

PIMENTA, Selma Garrido. Saberes pedagógicos e atividade docente. 8 ed. São Paulo: Cortez, 2012.

RIBAS, Mariná Holzmann; Et al. Formação de Professores: escolas, práticas e saberes. Ponta Grossa: Ed. UFPG, 2005.

ROMANOWSKI, Joana Paulin. Formação e profissionalização docente. 3ed. Curitiba: Ibpex, 2007.

SHIROMA, Eneida Oto; LIMA FILHO, Domingos Leite. Trabalho docente na Educação Profissional e Tecnológica e no PROEJA. Revista Educ. Soc., Campinas, v. 32, n. 116, p. 725-743, jul.-set. 2011. Disponível em: http://www.cedes.unicamp.br, acessado em: 30 jul 2015 .

TARDIF, Maurice. Saberes docentes e formação profissional. 17ed. Petrópoles: RJ: Vozes, 2014.

URBANETZ, Sandra Terezinha. O percurso formativo de docentes da educação profissional e o significado da docência na vida de engenheiros que se tornaram 
professores. Revista Brasileira de Pesquisa sobre Formação Docente. Vol. 3, n5, Ago-Dez: 2011. Disponível em: http://formacaodocente.autentica editora.com.br/, acessado em: 30 jun 2015.

ZANCHET, Beatriz Atrib. Et al. Motivações, primeiras experiências e desafios: o que expressam os docentes universitários iniciantes? Revista Brasileira de Pesquisa sobre Formação Docente. Vol. 4, $\mathrm{n}^{\circ} 6, \quad$ Jan-Jul: 2012. Disponível em: http://formacaodocente.autenticaeditora.com.br/, acessado em: 30 jun 2015. 